\title{
1 Arctic sea-ice loss fuels extreme European snowfall
}

2 Hannah Bailey ${ }^{1}$, Alun Hubbard ${ }^{2,3}$, Eric S. Klein ${ }^{4}$, Kaisa-Riikka Mustonen ${ }^{1}$, Pete D. Akers ${ }^{5}$,

3 Hannu Marttila ${ }^{6}$, and Jeffrey M. Welker ${ }^{1,7}$

4

$5 \quad{ }^{1}$ Ecology and Genetics Research Unit, University of Oulu, 90014 Oulu, Finland

$6 \quad{ }^{2}$ Centre for Arctic Gas Hydrate, Environment and Climate, Department of Geosciences, UiT

7 the Arctic University of Norway, 9037 Troms $\varnothing$, Norway

$8{ }^{3}$ Kvantum Institute, University of Oulu, 90014 Oulu, Finland

$9{ }^{4}$ Department of Geological Sciences, University of Alaska Anchorage, Anchorage, AK 99508,

10 U.S.A.

$11{ }^{5}$ Institut des Géosciences et l'Environnement, National Centre for Scientific Research,

12 Grenoble 38400, France

${ }^{6}$ Water, Energy and Environmental Engineering Research Unit, University of Oulu, 90014

Oulu, Finland

${ }^{7}$ Department of Biological Sciences, University of Alaska Anchorage, Anchorage, AK 99508,

U.S.A. 
The accelerated loss of Arctic sea-ice has been implicated with severe cold and snowy mid-latitude winters. However, the mechanisms and a direct link remain elusive due to limited observational evidence. Here we present atmospheric water vapour isotope measurements from Arctic Finland during "the Beast from the East" - a severe anticyclonic outbreak that brought heavy snowfall and freezing across Europe in February 2018. We find that an anomalously warm Barents Sea, with a $60 \%$ ice-free surface, supplied up to

$9.3 \mathrm{~mm} \mathrm{~d}^{-1}$ moisture flux to this cold north-easterly airflow. We demonstrate that approximately 140 gigatonnes of water was evaporated from the Barents Sea during the event, supplying up to $88 \%$ of the corresponding fresh snow over Northern Europe.

Reanalysis data show that from 1979 to 2020, net March evaporation across the Barents Sea increased by approximately $70 \mathrm{~kg}$ per square metre of sea-ice lost $\left(r^{2}=0.73, p<0.01\right)$, concurrent with a $1.6 \mathrm{~mm}$ (water equivalent) per year increase in Europe's maximum snowfall. Our analysis directly links Arctic sea-ice loss with increased evaporation and extreme snowfall, and signifies that by 2080 , an Atlantified ice-free Barents Sea will be a major source of winter moisture for continental Europe.

Arctic sea-ice plays a critical role in the hydrological cycle and global climate system ${ }^{1}$. In particular, the areal extent and concentration of sea ice controls thermodynamic and radiative processes driving water vapour, clouds, and aerosol feedbacks ${ }^{2}$. Accelerated sea ice loss over recent decades ${ }^{3}$ has been linked to increased surface evaporation and latent heat flux ${ }^{4,5}$, as well as localised increases in cloud formation, precipitation, and radiation absorption that further amplifies Arctic warming ${ }^{6-8}$. 

has decreased by $54 \%$ since $1979^{10}$ - an area of $~ 570,000 \mathrm{~km}^{2}$. This sea ice decline of 11,200 $\mathrm{km}^{2}$ per year ${ }^{3}$ has been accompanied by increasing snow mass trends across large areas of Eurasia that are adjacent to the Arctic Ocean ${ }^{11}$, particularly in autumn ${ }^{11-13}$. Evidence further suggests a dynamic link whereby autumn Barents-Kara sea-ice and snow cover anomalies in Eurasia can force extreme cold and snowy mid-latitude winters ${ }^{12,14-18}$. In part, this lagged connection reflects the vertical propagation of surface energy to the stratosphere, which can weaken the winter stratospheric polar vortex and induce strong anticyclonic flow over the Arctic Ocean ${ }^{17,18}$. These circulation anomalies manifest as phases of negative Arctic Oscillation (AO-) and North Atlantic Oscillation (NAO-) $)^{19,20}$, that can drive cold air advection and heavy snowfall across continental mid-latitudes, such as in winters 2009-10, 2010-11, 2012-13 and 2017-1821-24. However, a direct link between winter Barents sea-ice loss and the recent extreme snowy European winters ${ }^{25}$ has yet to be substantiated.

Here, we present empirical evidence for the direct impact of Arctic sea-ice decline on a severe winter weather event in Europe during February-March 2018. Popularly dubbed "the Beast from the East", the event coincided with strong NAO-circulation and drove anomalous low surface air temperatures (SAT) and heavy snowfall across Europe with severe socio-economic impacts ${ }^{22,23}$ (Fig. 1). We captured this event with continuous in situ measurements of atmospheric water vapour isotopes $\left(\delta^{18} \mathrm{O}, \delta^{2} \mathrm{H}\right)$ in Arctic Finland, providing unique observational constraints on the sea ice, moisture source, and kinematic processes during the event ${ }^{26-28}$. Specifically, we test the hypothesis that winter Barents sea-ice decline - and the expansion of warm open water - provides an incipient evaporative source of 


\section{The Beast from the East}

The spatial development of weekly composited sea level pressure (SLP) and SAT anomalies encompassing the February-March 2018 event are presented in Supplementary Figure 1. A major atmospheric precursor was the displacement and subsequent split of the stratospheric polar vortex on 11 February 2018, coincident with a major Sudden Stratospheric Warming (SSW) event ${ }^{22,29}$. The polar vortex split induced a dynamic reversal of the westerly zonal-mean winds poleward of $60^{\circ} \mathrm{N}$ at $10 \mathrm{hPa}$, triggering a marked temperature increase $\left(+33^{\circ} \mathrm{C}\right)$ over the polar stratosphere lasting $\sim 20$ days ${ }^{22}$. The successive downward migration of easterly winds to the troposphere ${ }^{22}$ favoured the development of a strong NAO- surface response with a large region of high pressure over Northern Scandinavia and the Barents Sea ${ }^{23}$ (Fig. 1a). Between 19 February and 5 March this strong anticyclone steered Arctic airflow directly into Europe, driving extreme negative SAT anomalies and heavy snowfall (Fig. 1). Blizzards were acutely disruptive across the British Isles and Western Europe where the Arctic outbreak converged with a deep Atlantic cyclone in early March ("Storm Emma") 23. Europe was subsequently hit by a second cold wave beginning 14 March when a consecutive anticyclone anchored over Scandinavia and drove Arctic airflow across the continent ${ }^{29}$ (Supplementary Figure 1).

Stable isotope and automated weather station (AWS) measurements were recorded at the Finnish Meteorological Institute's Sammaltunturi station in Pallas-Yllästunturi National Park, Arctic Finland (hereafter "Pallas"; $67.973^{\circ} \mathrm{N}, 24.116^{\circ} \mathrm{E} ; 565 \mathrm{~m}$ asl), and capture the 7-week period before and after the polar vortex split (see Methods). AWS measurements indicate the build-up of high-pressure beginning 11 February coincident with 
the SSW and anticyclogenesis over the Barents Region (Fig. 2 and Supplementary Fig. 1). Maximum barometric pressure at Pallas was attained on 28 February ( $980 \mathrm{hPa}$ ), equivalent to $1055 \mathrm{hPa}$ SLP and coincident with the NAO- minima on 1 March (-1.7 $\sigma)$ (Fig. 2).

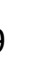

Prior to the event, mean vapour $\delta^{18} \mathrm{O}, \delta^{2} \mathrm{H}$, and deuterium (d)-excess values at Pallas were $-28.6 \%$ o $( \pm 4.3),-214.6 \%$ o $( \pm 36.3)$ and $14.1 \%$ \% \pm 4.9$)$ respectively (21 December 2017 -18 February 2018) (Fig. 2), where d-excess is calculated as $\delta^{2} \mathrm{H}-8 \cdot \delta^{18} \mathrm{O}^{30}$. While meteoric $\delta$-values reflect evaporation and condensation processes related to air mass temperature and saturation levels $\mathrm{s}^{30,31}$; $\mathrm{d}$-excess reflects and retains information pertaining to conditions at the evaporative source, primarily relative humidity $(\mathrm{RH})$ and sea surface temperature $(\mathrm{SST})^{32,33}$. Accordingly, Pallas $\delta^{18} \mathrm{O}$ values were positively correlated with local SAT $\left(r^{2}=0.5\right.$, $p<0.05)$. Moreover, whilst the lowest measured d-excess value $(1.3 \%$ ) coincided with the highest local SAT on 11 January $\left(1.0^{\circ} \mathrm{C}\right)$, maximum d-excess did not correspond to the lowest SAT on 24 January $\left(-24.4^{\circ} \mathrm{C}\right)$. Instead, beginning 19 February we captured a remarkable 16.0 $\%$ abrupt increase in d-excess at Pallas, culminating in maximum d-excess on 23 March (31.2\%o), and coinciding with increased snowfall over Northern Europe $\left(15-60^{\circ} \mathrm{E}, 50-70^{\circ} \mathrm{N}\right.$; Fig. 2c) and onset of the Beast from the East.

\section{Moisture flux at the sea-ice margin}

We used Lagrangian atmospheric back-trajectory modelling driven by the Global Data Assimilation System ${ }^{34}$ to diagnose the Pallas vapour origin and transport processes during the event (see Methods). Over the 14-week measurement period, our model output indicates four evaporative source regions: Barents (32\%), Atlantic (27\%), Eurasia (22\%) and Baltic (19\%) (Supplementary Fig. 2). However, northerly trajectories and snowfall during the 
event were supplied by moisture originating from the Barents Sea (Fig. 3a). At this time, the anticyclone drove cold, dry air over the ice pack across open water, where our modelled trajectories demonstrate a sharp increase in specific humidity due to intense evaporation along the sea ice edge $\left(+0.5 \mathrm{~g} \mathrm{~kg}^{-1}\right.$ per air parcel) (Fig. 3a). There is a corresponding deepening of the atmospheric boundary layer $(A B L)$ from $~ 100 \mathrm{~m}$ over the sea ice, to 2000 m-thick downstream of the ice margin due to strong turbulent and radiative processes (Supplementary Fig. 3). These processes are captured in MODIS satellite imagery as parallel cloud bands (or "cloud streets") that formed off the ice margin (Fig. 3b), indicating the development of a strongly heated convective $A B L$ with intense surface evaporation and condensation. Low level airflow advected the moisture south across the north Norwegian to sink of $<72$ hours (minimum $28 \mathrm{hr}$ ) (Supplementary Fig. 3). Barents Sea moisture advected to Europe during this period: 19 February-4 March, 14-20 March, and 23-28 March, each corresponding to increased continental snowfall and high vapour and precipitation d-excess (Fig. 2b,c and Supplementary Fig. 4). Meteoric vapour evaporation, when there is insufficient time for vapour to reach isotopic equilibrium with pack $(98 \% \mathrm{RH})$, the anomalously warm Barents SSTs $\left(2-5^{\circ} \mathrm{C}\right)$ (Fig. 1b) coupled with low near- 
northerly air flowed across the sea-ice/open-water boundary ${ }^{27,31}$. Furthermore, compared to atmospheric vapour originating from the Baltic and Eurasia regions, we find that Barents evaporate is characterised by relatively high mean $\delta^{18} \mathrm{O}$ values that are comparable to the Atlantic-derived evaporate (Supplementary Fig. 2). We attribute this to the welldocumented increased inflow of Atlantic water into the Barents Sea - the primary driver for marked sea ice loss in this Arctic warming hotspot ${ }^{9}$.

\section{Arctic sea-ice and European snowfall trends}

Our analyses identify the Barents Sea as a key source of atmospheric moisture during the 2018 event. Fundamental to this process was a 60\% ice-free, Atlantified sector of the Barents that enabled the direct transfer of latent energy from the ocean surface to the lower atmosphere. Using ERA5 reanalysis data ${ }^{35}$, we determine a net Barents moisture flux of 140 gigatonnes (Gt) to the atmosphere during the "Beast from the East" (19 February$28 \mathrm{March}$ ), attaining a maximum evaporation rate of $9.3 \mathrm{~mm} \mathrm{~d}^{-1}$ on 1 March coincident with the NAO minima (Fig. 2e). Global Snow Monitoring observations (GlobSnow) ${ }^{36}$ show a net snow mass increase of $159.2 \pm 2.9 \mathrm{Gt}$ (water equivalent) across Northern Europe over this 38-day period (Fig. 1b), indicating that Barents evaporation potentially contributed up to $\sim 88 \%$ to this fresh snow cover. By restricting our analysis to the initial pulse of Barents moisture advected to Northern Europe between 19 February and 4 March (Fig. 2, "Pulse 1") - thereby excluding the Atlantic influence from "Storm Emma" ${ }^{23}$ - we find that Barents evaporation potentially supplied $54 \mathrm{Gt}$ moisture to the atmosphere, equivalent to $69 \%$ of Northern Europe's net snow increase of $78.8 \pm 1.4 \mathrm{Gt}^{36}$ (Fig. 3e). This equates to a mean evaporative flux of $3.9 \mathrm{Gt} \mathrm{d}^{-1}$ from the Barents during Pulse 1 (Fig. 3c) that, under the prevailing northerly airflow, contributed $\sim 18.5 \%$ of the $21 \mathrm{Gt}$ daily mean total column water 
vapour (TCWV) over Northern Europe (surface to $850 \mathrm{hPa}$ ). By comparison, during a northerly winter outbreak from 13-19 March 197937, when Barents sea-ice cover was $\sim 640,000 \mathrm{~km}^{2}(56 \%)$ more extensive, a mean flux of only $1.4 \mathrm{Gt} \mathrm{d}^{-1}$ was evaporated off the Barents Sea (Fig. 3d). This represents $~ 4 \%$ of Northern Europe's mean TCWV budget during the 1979 event, and the corresponding snowfall accumulation was around half $(41.5 \pm 0.8$ Gt water equivalent) of that compared with Pulse 1 of the "Beast from the East".

Since 1979 the Barents Sea has been responsible for 95\% of the observed March seaice loss across the entire $\operatorname{Arctic}^{38}$. We use satellite observations of sea-ice ${ }^{10}$ and ERA5 reanalysis ${ }^{35}$ to investigate long-term dynamic links with atmospheric moistening in the Barents Region ${ }^{2,6}$, as well as increasing European extreme snowfall ${ }^{25}$ (see Methods). Between 1979-2020, we find a linear March Barents sea-ice decline of $\sim 11,200 \mathrm{~km}^{2} \mathrm{yr}^{-1}\left(\mathrm{r}^{2}=\right.$ $0.66, p<0.05)$ consistent with earlier estimates ${ }^{3}$, and a corresponding net March evaporation increase of $1.01 \mathrm{Gt} \mathrm{yr}^{-1}\left(\mathrm{r}^{2}=0.74, \mathrm{p}<0.05\right)$ (Fig. 4a). Over this period, Barents surface evaporation is negatively correlated with sea-ice area $\left(r^{2}=0.73, p<0.01\right)$, demonstrating a mean net March evaporative flux increase of 69.9 Gt per 1 million $\mathrm{km}^{2}$ seaice loss ( $70 \mathrm{~kg}$ per $\mathrm{m}^{2}$ ) (Fig. 4a). Moreover, we find that while mean March snowfall across Northern Europe has decreased by $8.2 \mathrm{~mm}$ (water equivalent) per decade since 1979, the maximum March snowfall - indicative of extreme heavy snowfall events ${ }^{24}$ - has increased by $16.0 \mathrm{~mm}$ per decade $\left(r^{2}=0.42, p<0.05\right)$, and is linearly congruent with increased Barents evaporation ( $\left.r^{2}=0.52, p<0.05\right)$ (Fig. 4a and Supplementary Fig. 5). increased localised evaporation in the Barents Region ${ }^{4,6}$, yet the long-term relationship has 
not been quantified across the Arctic, nor the direct and non-lagged seasonal link established with European winter snowfall. We explore these relationships by spatially regressing winter (December-March) ERA5 reanalysis fields ${ }^{35}$ and sea ice observations ${ }^{10}$ from 1979 to 2020. All fields are detrended and only relationships significant at the $95 \%$ confidence level considered (see Methods). Since 1979, winter surface evaporation across the Barents Region is negatively correlated with winter sea-ice area, with strong relationships also apparent in the Chukchi and Bering Seas $\left(r^{2}>-0.5 ; p<0.05\right)$ (Fig. 4b). Moreover, we find that European snowfall anomalies positively correlate with Barents evaporation, whereby enhanced evaporation increases heavy snowfall across Northern Europe (Fig. 4c). Whilst these relationships are particularly robust across Fennoscandia with coefficients up to $r^{2}=0.7(p<0.05)$, the influence of declining Barents sea-ice also spans a $20^{\circ}$ latitudinal range across Northern Europe, extending across the Baltic states and south into Russia (Fig. 4c).

\section{Implications of projected ice-loss}

The Barents Sea was a hotbed of extreme moisture flux during the Beast from the East in 2018. The pulses of high d-excess moisture that we observe being advected from the Barents into Europe represent a 'smoking gun' confirming our back-trajectory analyses that the vapour originated from increasingly exposed Arctic waters. Given projections of a winter ice-free Barents Sea by $2061-2088^{39}$, our observations support a future increase of locallysourced high-latitude atmospheric moisture and precipitation across the $\operatorname{Arctic}^{4,40,41}$. Our analysis further signifies an increased potential for extreme winter snowfall across Northern Europe where temperatures remain sufficiently cold to yield snow, for example under prevailing cold northerly airflow conditions such as those associated with weakened 
stratospheric polar vortex events and/or NAO- circulation ${ }^{13,17,42}$. Whether or not this effect is sustainable in the long-term under current and projected mean rates of warming ${ }^{1,43}$ warrants further investigation, including the potential for moist Arctic air masses to thermodynamically offset (or exceed) the atmospheric cooling associated with these events $^{43,44}$. It is widely considered that the poleward transport and convergence of moisture into the Arctic from lower latitudes is the fundamental mechanism for future Arctic amplification of the hydrologic cycle $e^{45,46}$. We conclude that an increasingly exposed, ice-free Arctic Ocean also provides an important local supply of atmospheric moisture that is a major source of winter precipitation for continental Europe.

\section{References}

1. Screen, J. A. et al. Consistency and discrepancy in the atmospheric response to Arctic sea-ice loss across climate models. Nat. Geosci. 11, 155-163 (2018).

2. Vihma, T. et al. The atmospheric role in the Arctic water cycle: A review on processes, past and future changes, and their impacts. J. Geophys. Res. Biogeosci. 121, 586-620 (2016).

3. Stroeve, J. \& Notz, D. Changing state of Arctic sea ice across all seasons. Environ. Res. Lett 13, 103001 (2018).

4. Bintanja, R. \& Selten, F. M. Future increases in Arctic precipitation linked to local evaporation and sea-ice retreat. Nature 509, 479-482 (2014).

5. Kim, K. Y. et al. Vertical Feedback Mechanism of Winter Arctic Amplification and Sea Ice Loss. Sci. Rep. 9, 1-10 (2019). 
6. Boisvert, L. N., Wu, D. L. \& Shie, C.-L. Increasing evaporation amounts seen in the Arctic between 2003 and 2013 from AIRS data. J. Geophys. Res. Atmos. 120, 68656881 (2015).

7. Kopec, B. G., Feng, X., Michel, F. A. \& Posmentier, E. S. Influence of sea ice on Arctic precipitation. Proc. Natl. Acad. Sci. U. S. A. 113, 46-51 (2016).

8. Jun, S.-Y., Ho, C.-H., Jeong, J.-H., Choi, Y.-S. \& Kim, B.-M. Recent changes in winter Arctic clouds and their relationships with sea ice and atmospheric conditions. Tellus $A$ 68, 29130 (2016).

9. Lind, S., Ingvaldsen, R. B. \& Furevik, T. Arctic warming hotspot in the northern Barents Sea linked to declining sea-ice import. Nat. Clim. Change. 8, 634-639 (2018).

10. Fetterer, F., Knowles, K., Meier, W. N., Savoie, M. \& Windnagel, A. K. Sea Ice Index, Version 3 | National Snow and Ice Data Center. (2017) https://nsidc.org/data/seaice_index/archives.

11. Pulliainen, J. et al. Patterns and trends of Northern Hemisphere snow mass from 1980 to 2018. Nature 581, 294-298 (2020).

12. Cohen, J. et al. Recent Arctic amplification and extreme mid-latitude weather. Nat. Geosci. 7, 627-637 (2014).

13. Cohen, J. L., Furtado, J. C., Barlow, M. A., Alexeev, V. A. \& Cherry, J. E. Arctic warming, increasing snow cover and widespread boreal winter cooling. Environ. Res. Lett. 7, 014007 (2012). 
14. Mori, M., Kosaka, Y., Watanabe, M., Nakamura, H. \& Kimoto, M. A reconciled estimate of the influence of Arctic sea-ice loss on recent Eurasian cooling. Nat. Clim. Change 9, 123-129 (2019).

15. Kim, B. M. et al. Weakening of the stratospheric polar vortex by Arctic sea-ice loss. Nat. Commun. 5, 1-8 (2014).

16. Mori, M., Watanabe, M., Shiogama, H., Inoue, J. \& Kimoto, M. Robust Arctic sea-ice influence on the frequent Eurasian cold winters in past decades. Nat. Geosci. 7, 869873 (2014).

17. Liu, J., Curry, J. A., Wang, H., Song, M. \& Horton, R. M. Impact of declining Arctic sea ice on winter snowfall. Proc. Natl. Acad. Sci. U. S. A 109, 4074-4079 (2012).

18. Cohen, J. et al. Divergent consensuses on Arctic amplification influence on midlatitude severe winter weather. Nat. Clim. Change 10, 20-29 (2020).

19. Pedersen, R. A., Cvijanovic, I., Langen, P. L. \& Vinther, B. M. The Impact of Regional Arctic Sea Ice Loss on Atmospheric Circulation and the NAO. J. Clim. 29, 889-902 (2016).

20. Yang, X.-Y., Yuan, X. \& Ting, M. Dynamical Link between the Barents-Kara Sea Ice and the Arctic Oscillation. J. Clim. 29, 5103-5122 (2016).

21. Jung, T., Vitart, F., Ferranti, L. \& Morcrette, J. J. Origin and predictability of the extreme negative NAO winter of 2009/10. Geophys. Res. Lett. 38, (2011).

22. Lü, Z., Fei, L. I., Orsolini, Y. J., Yongqi, G. A. O. \& Shengping, H. E. Understanding of European cold extremes, sudden stratospheric warming, and Siberian snow accumulation in the winter of 2017/18. J. Clim. 33, 527-545 (2020). 
23. Greening, K. \& Hodgson, A. Atmospheric analysis of the cold late February and early March 2018 over the UK. Weather 74, 79-85 (2019).

24. Cohen, J., Jones, J., Furtado, J. C. \& Tziperman, E. Warm Arctic, cold continents a common pattern related to Arctic sea ice melt, snow advance, and extreme winter weather. Oceanography 26, 150-160 (2013).

25. Faranda, D. An attempt to explain recent changes in European snowfall extremes. Weather and Clim. Dynam. 1, 445-458 (2020).

26. Galewsky, J. Constraining supersaturation and transport processes in a south American cold-air outbreak using stable isotopologues of water vapor. J. Atmos. Sci. 72, 2055-2069.pdf (2015).

27. Klein, E. S. et al. Arctic cyclone water vapor isotopes support past sea ice retreat recorded in Greenland ice. Sci. Rep. 5, 1-9 (2015).

28. Kurita, N. Origin of Arctic water vapor during the ice-growth season. Geophys. Res. Lett. 38, 1-5 (2011).

29. Overland, J. et al. The Polar Vortex and Extreme Weather: The Beast from the East in Winter 2018. Atmosphere 11, 664 (2020).

30. Dansgaard, W. Stable isotopes in precipitation. Tellus 16, 436-468 (1964).

31. Bailey, H. L., Klein, E. S. \& Welker, J. M. Synoptic and Mesoscale Mechanisms Drive Winter Precipitation $8180 / \delta 2 \mathrm{H}$ in South-Central Alaska. J. Geophys. Res. Atmos. 124, 4252-4266 (2019). 
32. Bonne, J. L. et al. Resolving the controls of water vapour isotopes in the Atlantic sector. Nat. Commun. 10, 1-10 (2019).

33. Pfahl, S. \& Sodemann, H. What controls deuterium excess in global precipitation? Clim. Past 10, 771-781 (2014).

34. Stein, A. F. et al. Noaa's hysplit atmospheric transport and dispersion modeling system. Bull. Amer. Meteor. 96, 2059-2077 (2015).

35. Hersbach, H. et al. The ERA5 global reanalysis. Q. J. R. Meteorol. Soc. 146, 1999-2049 (2020).

36. Luojus, K., Pulliainen, J., Takala, M., Lemmetyinen, J. \& Moisander, M. GlobSnow v3.0 snow water equivalent (SWE). PANGAEA (2020) https://doi.org/10.1594/PANGAEA.911944.

37. Smith, E. T. \& Sheridan, S. C. Where do Cold Air Outbreaks occur and how have they changed over time? Geophys. Res. Lett. 47 (2020) doi:10.1029/2020gl086983.

38. Onarheim, I. H., Eldevik, T., Smedsrud, L. H. \& Stroeve, J. C. Seasonal and regional manifestation of Arctic sea ice loss. J. Clim. 31, 4917-4932 (2018).

39. Onarheim, I. H. \& Årthun, M. Toward an ice-free Barents Sea. Geophys. Res. Lett. 44, 8387-8395 (2017).

40. Boisvert, L. N. \& Stroeve, J. C. The Arctic is becoming warmer and wetter as revealed by the Atmospheric Infrared Sounder. Geophys. Res. Lett. 42, 4439-4446 (2015).

41. Bintanja, R. \& Andry, O. Towards a rain-dominated Arctic. Nat. Clim. Chang. 7, 263267. 
42. Huang, J. \& Tian, W. Eurasian Cold Air Outbreaks under different arctic stratospheric polar vortex strengths. J. Atmos. Sci 76, 1245-1264 (2019).

43. Ayarzagüena, B. \& Screen, J. A. Future Arctic sea ice loss reduces severity of cold air outbreaks in midlatitudes. Geophys. Res. Lett. 43, 2801-2809 (2016).

44. Screen, J. A. The missing Northern European winter cooling response to Arctic sea ice loss. Nat. Commun. 8, 14603 (2017).

45. Bintanja, R. et al. Strong future increases in Arctic precipitation variability linked to poleward moisture transport. Sci. Adv. 6, vol 7, eaax6869 (2020).

46. Zhang, X. et al. Enhanced poleward moisture transport and amplified northern highlatitude wetting trend. Nat. Clim. Chang. 3, 47-51 (2013).

\section{Corresponding author}

Correspondence to Hannah Bailey (hannah.bailey@oulu.fi).

\section{Acknowledgements}

This study was funded by an Academy of Finland grant (316014) and University of the Arctic (UArctic) Research Chairship to J.M.W. H.B. acknowledges support by the Academy of Finland and a UArctic Postdoctoral Fellowship. A.H. was supported by an Arctic Interactions Grant from the Kvantum Institute, University of Oulu. The authors thank Juha Hatakka and the Finnish Meteorological Institute and staff working at the Sammaltunturi Station. Valtteri Hyöky (Metsähallitus) helped maintain the Picarro instrumentation and assisted with the humidity-isotope calibrations. Pertti Ala-Aho assisted during the December 2017 field 
campaign. The NOAA Air Resources Laboratory is acknowledged for the provision of the HYSPLIT model used in this publication. Lastly, we thank Jean-Louis Bonne for constructive comments on this paper.

\section{Author Contributions}

347 H.B. conducted the research, created the figures, and wrote the manuscript. H.B., A.H., E.S.K. and J.M.W (Project PI) conceived and designed the study. J.M.W., E.S.K., K-R.M. and H.M. conducted the fieldwork. K-R.M., E.S.K., H.M. and P.D.A. performed and/or contributed to the isotope data measurements and post-processing. H.B. and A.H. performed the back-trajectory and long-term analyses. All authors contributed comments and/or revisions to the manuscript.

\section{Competing Interests}

The authors declare no competing interests.

\section{Figure captions}

Figure 1. Synoptic climatology during the Beast from the East. Maps show (a) daily composited near surface $(2 \mathrm{~m})$ air temperature $(T)$ and sea level pressure anomalies, and (b) sea surface temperature (SST) anomalies and total snowfall ${ }^{36}$, over the period from 19 February to 28 March 2018. Anomalies are calculated relative to the $1981-2010$ baseline ${ }^{35}$. High $(\mathrm{H})$ and low $(\mathrm{L})$ pressure centres are indicated in $(\mathbf{a})$, and mean sea ice cover ${ }^{10}$ is depicted in (b) as light grey shading. The black square indicates the Pallas field site location in Arctic Finland. 
Figure 2. Observations during winter 2017-18. Timeseries show Pallas (a) vapour (line) and snow (circles) $\delta^{18} \mathrm{O}$ (blue) and $\delta^{2} \mathrm{H}$ (red), (b) vapour (blue lines) and snow (circles) d-excess, (c) Pallas barometric pressure (570 m asl) and daily snowfall ${ }^{36}$ (bars) over Northern Europe (asterisks indicate missing data), (d) Pallas vapour mixing ratio (red) and air temperature (blue), and (e) positive (red) and negative (blue) NAO index values. Pallas data represent 5minute averages, and daily mean vapour $\mathbf{d}$-excess is also shown in (b) by the thick blue line. Blue columns indicate three pulses of Barents moisture advected to Europe during the Beast from the East (black dashed lines). NAO data in (e) were obtained from the National Weather Service Climate Prediction Center (https://www.cpc.ncep.noaa.gov/data).

Figure 3. Barents Sea moisture advection to Northern Europe. (a) Back-trajectories from Pallas (square) between 19-27 February 2018 and associated mean vapour d-excess and $\delta^{18} \mathrm{O}$. Colours depict hourly specific humidity changes $(\Delta \mathrm{q})$, where a positive (negative) $\Delta \mathrm{q}$ indicates a moisture increase (decrease) due to evaporation (precipitation). Grey circles indicate either no net moisture change or a change above the ABL; (b) Aqua-MODIS satellite image showing Barents "cloud streets"; (c) daily mean evaporation during outbreaks in 2018 and (d) 1979, and (e) Northern Europe snow mass ${ }^{36}$ increase during the interval in (d). Black/blue solid lines in (a,c-e) show mean sea-ice edge ${ }^{10}$, grey isolines in c-e represent mean $\mathrm{SLP}^{35}$ (4 $\mathrm{hPa}$ intervals).

Figure 4. Historical Arctic sea-ice and atmospheric moisture links. (a) Linear trends and regression (inset) of the 3-yr running mean March Barents sea-ice area (blue) and net surface evaporation (red), and Northern Europe's maximum March snow mass (grey bars) between 1979-2020. Spatial regression coefficients of detrended winter (December-March) 


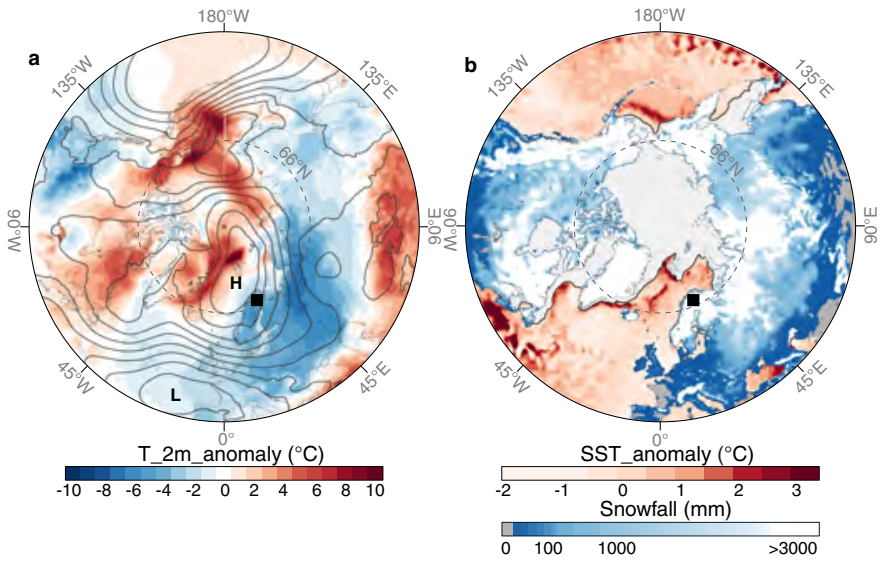




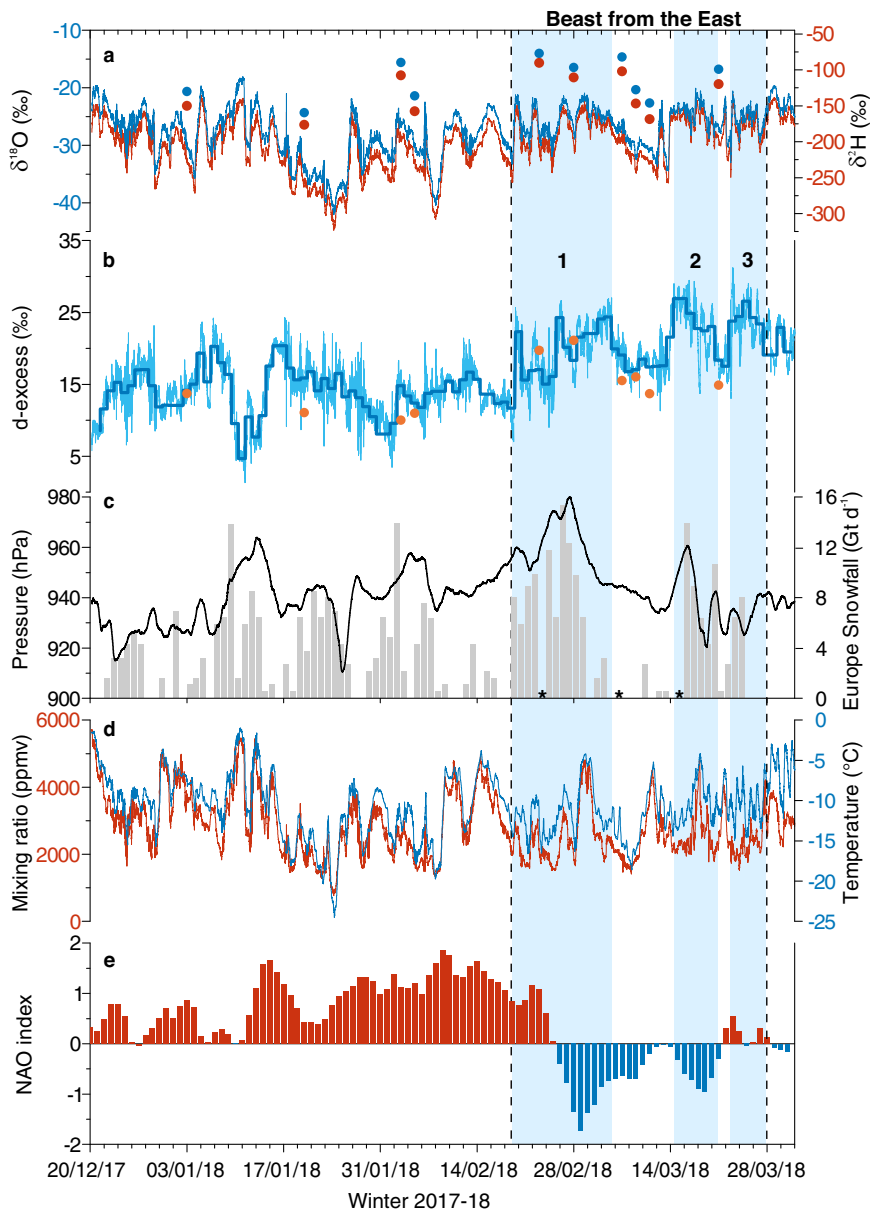



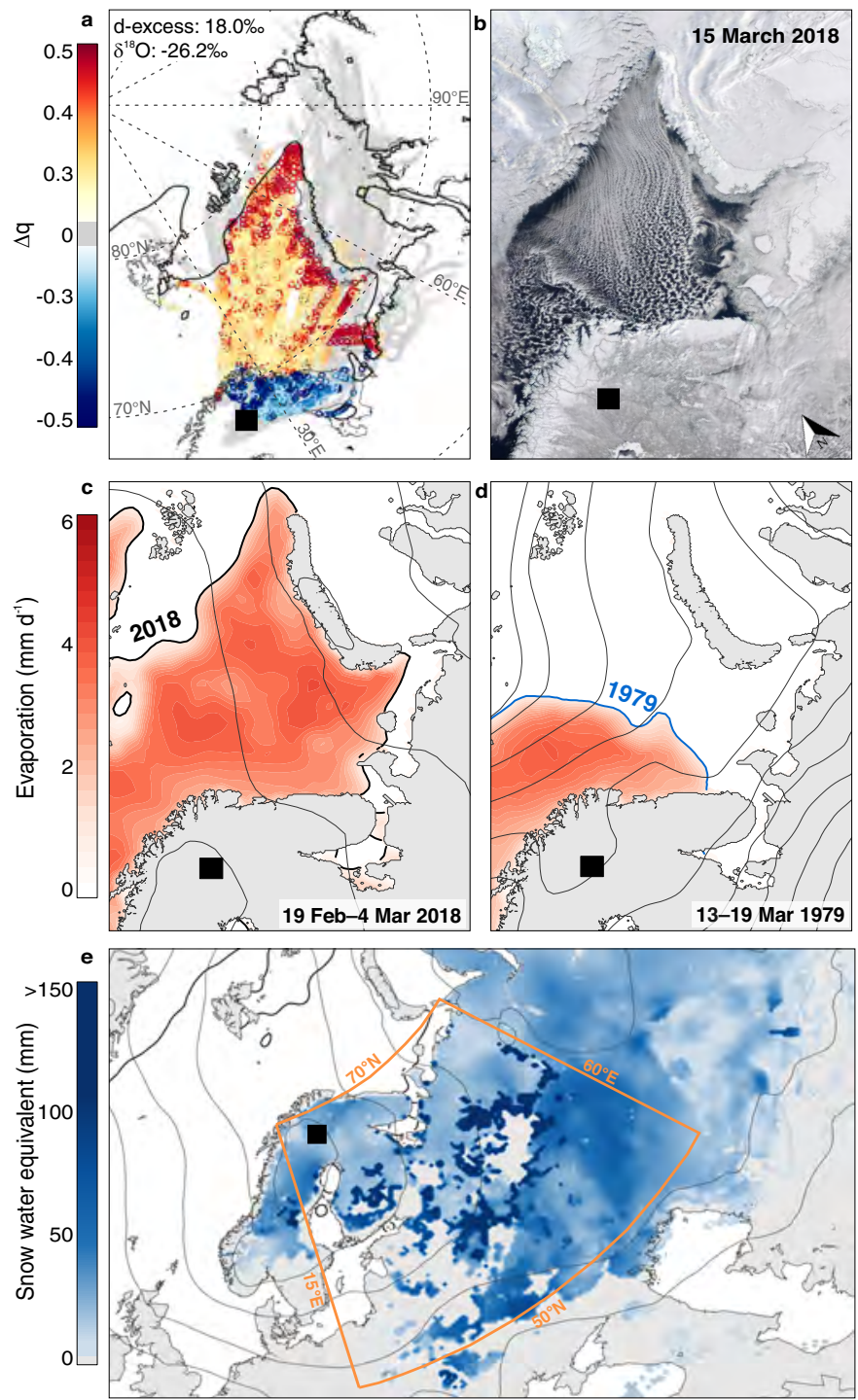


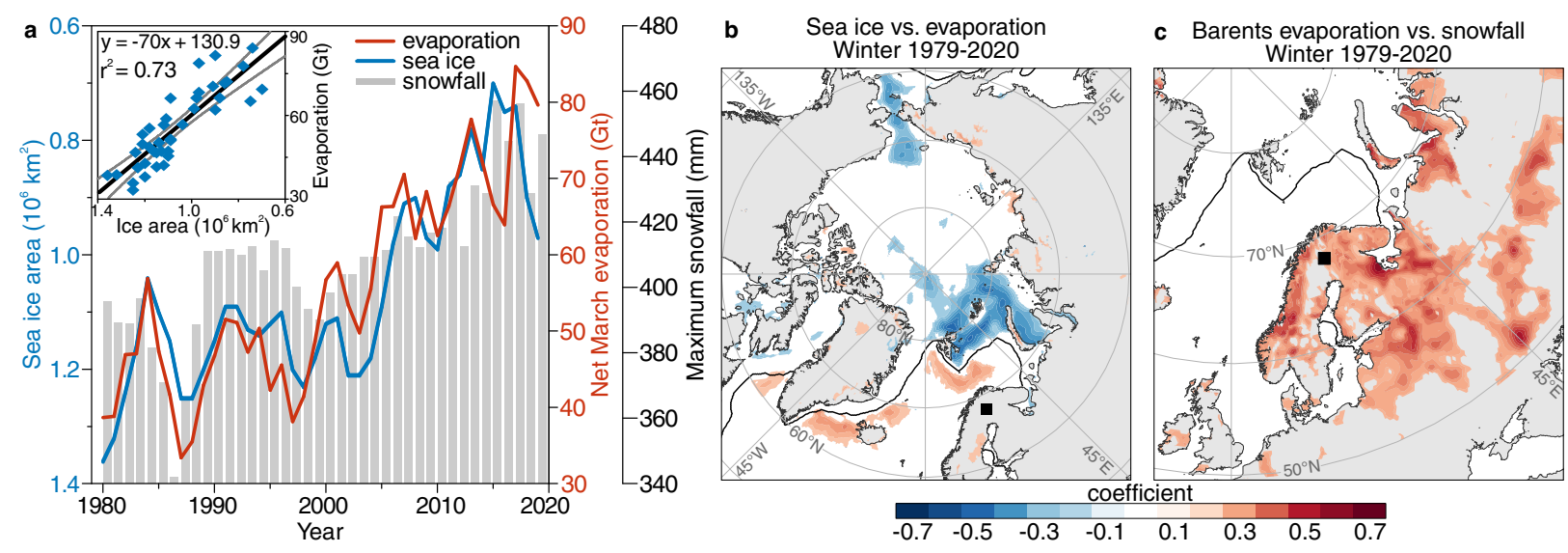

